\title{
A Comparative Study of Voltage, Peak Current and Dual Current Mode Control Methods for Noninverting Buck-Boost Converter
}

\author{
Marko Č. Bošković
}

\begin{abstract}
This paper presents a comparison of voltage mode control (VMC) and two current mode control (CMC) methods of noninverting buck-boost converter. The converter control-to-output transfer function, line-to-output transfer function and the output impedance are obtained for all methods by averaging converter equations over one switching period and applying small-signal linearization. The obtained results are required for the design procedure of feedback compensator to keep a system stable and robust. A comparative study of VMC, peak current mode control (PCMC) and dual-current mode control (DCMC) is performed. Performance evaluation of the closed-loop system with obtained compensator between these methods is performed via numerical simulations.

Keywords - Noninverting buck-boost converter, Voltage mode control, Current mode control, Performance
\end{abstract}

\section{INTRODUCTION}

$\mathrm{B}$ UCK-BOOST (step-down and step-up) converters are widely used in industrial personal computers (IPCs), point-of-sale (POS) systems and automotive start-stop systems [1]. A wide area of application of non-inverting buck-boost converter is battery charging and discharging [2]-[4], where there is a need to have a supply voltage higher and lower than the battery voltage. In this way, by efficient control techniques it is possible to prolong the battery life. There are a number applications of noninverting buck boost converter, where it acts as an intermediate power stage such as for obtaining a high degree of power factor correction (PFC) [5-7], maximum power point tracking (MPPT) of solar panels [8], [9], fuel cell regulation [10], [11], battery charging in plug-in hybrid electrical vehicles [12], [13], etc.

Fig. 1 presents the schematic of the power stage of noninverting buck-boost converter with two switches and a single inductor, known as a buck-cascaded buck-boost converter which is the most suitable for portable, costeffective, low-voltage applications [1].

Paper received May 1, 2016; revised July 5, 2016; accepted July 5, 2016. Date of publication July 20, 2016. The associate editor coordinating the review of this manuscript and approving it for publication was Prof. Nataša Nešković.

This paper is a revised and expanded version of the student paper presented at the 23rd Telecommunications Forum TELFOR 2015 [23].

Marko Č. Bošković is with the Faculty of Electrical Engineering, University of East Sarajevo, Vuka Karadžića 30, 71123 East Sarajevo, Bosnia and Herzegovina (phone: +38757342788; e mail: marko.boskovic@etf.unssa.rs.ba).
By adequate control it can be operated in buck, boost and buck-boost mode. However, by considering the efficiency, practice has proved that it is more used either in buck mode or in boost mode depending on a particular application.

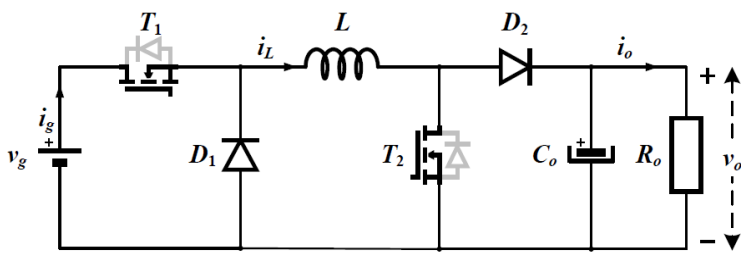

Fig. 1. Power stage of non-inverting buck.

In order to simplify the control design procedure, in this paper, both power switches $T_{1}$ and $T_{2}$ are simultaneously driven with the same gate signal, so buck-boost mode is used in a continuous conduction mode of inductor current. It means that diodes $D_{1}$ and $D_{2}$ are on whenever power switches $T_{1}$ and $T_{2}$ are off. When a duty cycle is less than 0.5 , the output voltage is lower than the input (buck mode), and for a duty cycle greater than 0.5 , the output voltage is higher than the input (boost mode).

This paper is primarily focused on the performance comparison of three control methods, voltage mode control (VMC), and two current mode control methods (peak current mode control - PCMC and dual current mode control - DCMC). In order to obtain high performance control of the system, a good model of the system is required. A model of the system can be derived by using measurements of the system, i.e. system identification. Although, the converter is a time-variant system, by an adequate method it may be analytically approximated with a time-invariant model. From the obtained model, it is possible to extract three major transfer functions: the control-to-output transfer function, line-to-output transfer function and the output impedance, which represent the effects of the control signal, the input voltage and load current, respectively, on the output voltage [14]. In this paper, a converter model is obtained by averaging converter equations over one switching period and applying smallsignal linearization.

This paper is organized as follows. Primary characteristics of VMC, PCMC and DCMC techniques are considered in Section 2. Small-signal models and appropriate transfer functions are developed and a compensator design procedure is given in Section 3 . 
Simulation results are presented in Section 4 and concluding remarks are specified in Section 5.

\section{VMC, PCMC AND DCMC CONTROL METHODS OF NONINVERTING BUCK-BOOST CONVERTER}

Fig 2 presents block diagrams of VMC, PCMC and DCMC control methods with obtained compensator $G_{c}(s)$. VMC method has a single control loop where a duty cycle is directly controlled by a voltage derived from the reference voltage $v_{\text {ref }}$ and sensed output voltage $v_{\mathrm{o}}$. In addition to a voltage loop, PCMC and DCMC methods contain an inner current loop which directly controls inductor current, while the output voltage is controlled indirectly by a current loop. A more detailed operation principle and key features of particular control methods are considered and analyzed below.

\section{A. Voltage Mode control}

The term VMC arises from the fact that the duty cycle is linearly proportional to the control voltage, why it is also called duty ratio control. This proportional gain depends on the peak-to-peak value of the saw-tooth signal. It is characterized by simplicity and is still popular in point-ofload DC/DC converters [1]. A principled scheme of VMC is illustrated in Fig. 2. a).

In order to get a superior dynamic line response for VMC, line feed-forward may be used. However, this feature is often avoided because of a complex expression for the DC gain of control-to-output transfer function which requires complex implementation. In Section 3, it will be shown that control-to-output transfer function is of the second order and contains a right-half plane (RHP) zero. This non-minimum phase system causes considerable difficulties to the feedback compensation design [15] and is a reason why various $\mathrm{CMC}$ techniques with simplified structures have been commonly applied.

\section{B. Current mode control}

Current-mode control methods can be classified into two groups: constant frequency and variable frequency control methods. The first group includes peak-current mode control, valley-current mode control, PWM conductance control with triangle-wave compensation, and average current mode control. The second group includes selfoscillating converters, controlled with constant on-time, constant off-time and hysteretic methods. CMC, compared with VMC, offer several advantages such as inherent line feed-forward property, automatic overload and short-circuit protection, and easy paralleling of multiple converters [16].

\section{1) Peak current mode control}

The most popular among CMC techniques is peak current mode control. A typical scheme of PCMC method is presented in Fig. 2 b). The peak value of the inductor current is here used to determine the moment to turn off the power switches [16]. Converter with PCMC has a faster response time than $\mathrm{VMC}$, and $\mathrm{PCMC}$ is widely used in DC converters and for power factor correction (PFC). However, a PCMC converter may be more noise sensitive than VMC. In PCMC technique, current limiting is obtained automatically since the peak current is controlled. The control of the inductor current in a continuous conduction mode is unstable if the steady-state duty cycle $D$ is greater than 0.5, and subharmonic oscillations appear in the inductor current waveform. It is unstable in the sense that the duty cycle $d(t)$ never reaches a constant level even if $v_{c}(t)$ is constant. To avoid stability problem, the control scheme is usually modified, by addition of an artificial ramp $i_{a}(t)$ to a sensed inductor current waveform. In this way, the instant when power switch is switched off is changed to the moment when it is satisfied $i_{L}(t)=i_{c}(t)-i_{a}(t)$.
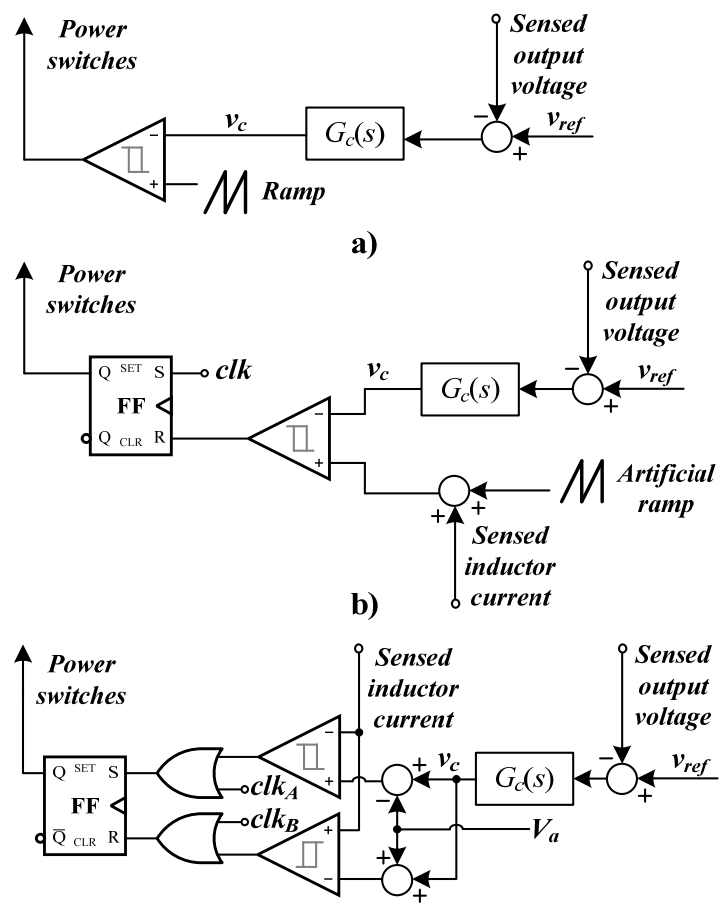

c)

Fig. 2. Block diagrams of the (a) VMC method; (b) PCMC method and (c) DCMC method with feedback compensator $G_{c}(s)$.

The characteristic value $\alpha$ is defined as

$$
\alpha=-\frac{m_{2}-m_{a}}{m_{1}+m_{a}},
$$

where $m_{a}$ is the slope of $i_{a}(t), m_{1}=v_{g} / L$ is the slope when switches $T_{1}$ and $T_{2}$ are on, and $m_{2}=v_{o} / L$ when both switches are off. The value of $\alpha$ should be selected such that $|\alpha|<1$ to obtain stability which is satisfied for a sufficiently large value of $m_{a}$ [16]. However, the use of a large compensation ramp to increase the range of $d$ is not practical. This problem can be solved by the use of variable switching frequency: hysteretic control method, and discontinuous control mode, as was pointed out in [8].

\section{2) Dual current-mode control}

In order to achieve stability for the entire duty-cycle range, DCMC is proposed in [17], and it represents the constant frequency current mode control method. The block diagram of DCMC circuit is presented in Fig. 2. c). There 
are two clock signals clk $\mathrm{k}_{\mathrm{A}}$ and $\mathrm{clk}_{\mathrm{B}}$, both with constant and the same frequency, and one has a delay with respect to the other of a half period. It should be noted that DCMC has no slope compensation. For proper and stable operation of DCMC, the band voltage $2 V_{a}$ must be selected to be larger than or equal to the maximum peak-to-peak ripple of the inductor current $\Delta i_{L p p \text { max }}$. This condition can be expressed by the following relation

$$
2 V_{a}>K_{i L} R_{L} \Delta i_{L p p \max }=K_{i L} R_{L} \max \left\{\frac{1}{L f_{s}\left(1 / v_{o}+1 / v_{g}\right)}\right\}
$$

where $K_{i L}$ is a measuring gain, $R_{L}$ is a resistor used to translate inductor current into voltage $v_{c}, \Delta i_{L p p \max }$ is the maximum value which may be defined depending on the limits of input/output voltage in a specific application. However, this can adversely affect the waveform of inductor current and output voltage, especially in applications with PFC circuits and inverters because a significant peak-to-average error in the inductor current would exist [18]. If the band is not large enough, the operation is not proper, due to modulator operation is almost as hysteretic current mode circuit [17]. A large value of $V_{a}$ is also not recommendable since it introduces a large domain of uncontrolled output current when the duty-cycle is 0.5 . A possible way to solve this drawback of DCMC is to use adaptive band voltage as was elaborated in [18].

\section{SMALL-SIGNAL ANALYSIS}

The most common methods for modeling DC/DC converters are injected approach, circuit averaging and the state-space averaging method. The end results of nearly all methods are equivalent [19].

\section{A. Modeling of noninverting buck-boost converter}

Small-signal averaged equations for noninverting buckboost converter from Fig. 1 operating in a continuous conduction mode are

$$
\begin{aligned}
& L \frac{d \hat{i}_{L}(t)}{d t}=D \hat{v}_{g}(t)-D^{\prime} \hat{v}_{o}(t)+\left(V_{g}+V_{o}\right) \hat{d}(t) \\
& C \frac{d \hat{v}_{o}(t)}{d t}=D^{\prime} \hat{i}_{L}(t)-\frac{\hat{v}_{o}(t)}{R}-I_{L} \hat{d}(t) \\
& \hat{i}_{g}(t)=D \hat{i}_{L}(t)+I_{L} \hat{d}(t)
\end{aligned}
$$

where $\hat{v}_{g}(t), \hat{v}_{o}(t), \hat{i}_{g}(t), \hat{i}_{L}(t)$ and $\hat{d}(t)$ are small AC variations superimposed to quiescent values $V_{g}, V_{o}, I_{g}, I_{L}$ and $D$ of input and output voltage, input and output current and duty cycle, respectively. By applying the principles of inductor volt-second and capacitor charge balance, one obtains quiescent values of $V_{o}, I_{L}$ and $I_{g}$

$$
V_{o}=\frac{D}{D^{\prime}} V_{g}, I_{L}=\frac{V_{o}}{D^{\prime} R}, I_{g}=D I_{L}
$$

Fig. 3 presents a small-signal AC equivalent circuit of noninverting buck-boost converter corresponding to equations (3).

By applying the Laplace transforms in (3), duty cycle-tooutput transfer function $G_{v d}(s)$, line-to-output $G_{v g}(s)$, and output impedance $Z_{\text {out }}(s)$ are given with the following relations

$$
\begin{gathered}
G_{v d}^{\mathrm{VMC}}(s)=\left.\frac{\hat{v}_{o}(s)}{\hat{d}(s)}\right|_{\hat{v}_{g}(s)=0}=G_{d 0} \frac{1-\frac{s}{\omega_{z}}}{1+\frac{s}{Q \omega_{0}}+\left(\frac{s}{\omega_{0}}\right)^{2}} \\
G_{v g}^{\mathrm{VMC}}(s)=\left.\frac{\hat{v}_{o}(s)}{\hat{v}_{g}(s)}\right|_{\hat{d}(s)=0}=G_{g 0} \frac{1}{1+\frac{s}{Q \omega_{0}}+\left(\frac{s}{\omega_{0}}\right)^{2}} \\
Z_{\text {out }}^{\mathrm{VMC}}(s)=\frac{L}{D^{\prime 2}} \frac{s}{1+\frac{s}{Q \omega_{0}}+\left(\frac{s}{\omega_{0}}\right)^{2}}
\end{gathered}
$$

where $G_{d 0}=V_{o} / D D^{\prime}$ and $G_{g 0}=D / D^{\prime}$ are DC gains, $\omega_{z}=D^{\prime 2} R / D L$ is an angular frequency zero, $\omega_{o}=D^{\prime} / \sqrt{L C}$ corner frequency and $Q=D^{\prime} R \sqrt{C / L}$ a quality factor.

For modeling PCMC and DCMC, a simple first-order approximation is employed, in which the equality of the average inductor current $\left\langle\hat{i}_{L}(t)\right\rangle_{T_{s}}$ and control signal $i_{c}(t)=v_{c}(t) /\left(K_{i L} R_{L}\right)$ is assumed. This approximation is justified whenever inductor current ripple and artificial ramp have a negligible magnitudes [19]. Hence, it leads to

$$
K_{i L} \hat{i}_{L}(t)=\hat{v}_{c}(t) / R_{L},
$$

where $\hat{v}_{c}(t)$ is a small ac variation of control voltage due to variations in current reference $i_{c}(t)$. Without loss of generality, in this paper is taken $K_{i L}=1$ and $R_{L}=1 \Omega$. In general, the duty cycle depends not only on $i_{c}(t)$, but also on the converter voltages and currents. In this way, substitution of (8) in (3) leads to solution for $\hat{d}(s)$

$$
\hat{d}(s)=\frac{\frac{s L}{K_{i L} R_{L}} \hat{v}_{c}(s)-D \hat{v}_{g}(s)+D^{\prime} \hat{v}_{o}(s)}{V_{g}+V_{o}} .
$$

After eliminating $\hat{d}(s)$ from (3), and applying the Laplace transforms in newly formed equations, one obtains controlto-output transfer function $G_{v c}(s)$

$$
G_{v c}^{\mathrm{CMC}}(s)=\left.\frac{\hat{v}_{o}(s)}{\hat{v}_{c}(s)}\right|_{\hat{v}_{g}=0}=\frac{R D^{\prime}}{D+1} \frac{1-\frac{s}{\omega_{z}}}{1+\frac{s}{\omega_{p}}},
$$

line-to-output function $\mathrm{G}_{v g}(s)$

$$
G_{v g}^{\mathrm{CMC}}(s)=\left.\frac{\hat{v}_{o}(s)}{\hat{v}_{g}(s)}\right|_{\hat{v}_{c}=0}=\frac{D^{2}}{1-D^{2}} \frac{1}{1+\frac{s}{\omega_{p}}}
$$

and output impedance $Z_{\text {out }}(s)$

$$
Z_{\text {out }}^{\mathrm{CMC}}(s)=\frac{R}{1+D} \frac{1}{1+\frac{s}{\omega_{p}}}
$$




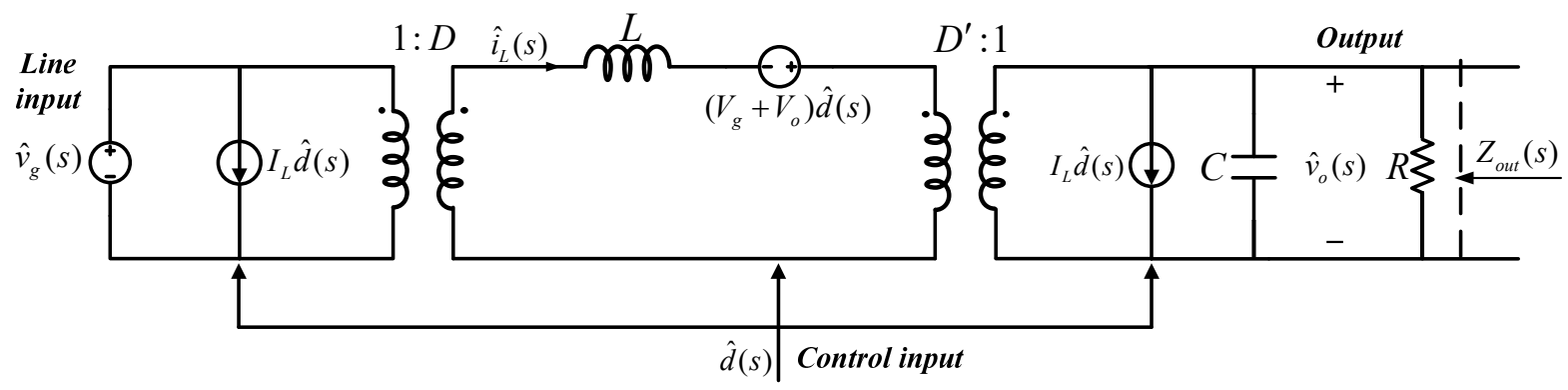

Fig. 3. Small-signal AC equivalent circuit model of the noninverting buck-boost converter.

where $\omega_{z}=D^{\prime 2} R / D L$ and $\omega_{p}=(D+1) / R C$ are angular frequencies, of zero and pole, respectively. As can be seen from relations (9)-(12), simplified first-order transfer functions are obtained.

For the purpose of obtaining a more precise relationship between the average inductor current and control input, a more accurate small-signal model may be used, as in [21].

\section{A. Design of feedback compensator $G_{c}(s)$}

A feedback loop must be designed to meet specifications regarding line disturbance rejection, transient response, output impedance, etc. To achieve this, an adequate feedback compensator $G_{\mathrm{c}}(s)$ should be designed. $G_{\mathrm{c}}(s)$ is here designed for the control-to-output transfer function marked as $G_{v x}(s)$, where index $x=d$ corresponds to VMC, and $x=c$ to CMC. Procedure starts with the selection of desired complementary sensitivity function $T(s)=L(s) /(1+L(s))$ where $L(s)=G_{\mathrm{c}}(s) G_{v x}(s)$ is a loop gain (feedback function) [20,21]. In order to obtain a maximum attenuation of disturbances, the compensator $G_{\mathrm{c}}(s)$ is defined as

$$
G_{c}(s)=\frac{1}{G_{v x}(s)} \frac{T(s)}{1-T(s)}
$$

By insight into obtained control-to-output transfer functions, (5) and (9), $T(s)$, should be selected as

$$
T(s)=\frac{\eta_{2} s^{2}+\eta_{1} s+1}{(\lambda s+1)^{2 n}}\left(1-\frac{s}{\omega_{z}}\right),
$$

In general, parameters $\eta_{1}, \eta_{2}$ are determined to cancel poles of the process $G_{v x}(s)$ and zeros of function $F(s)$

$$
F(s)=(\lambda s+1)^{2 n}-\left(\eta_{2} s^{2}+\eta_{1} s+1\right)\left(1-s / \omega_{z}\right) .
$$

The adjustable parameter of the compensator $G_{c}(s)$ is time constant $\lambda$. It is also possible to introduce an additional adjustable parameter, i.e. a factor of relative damping of the closed loop system $\zeta>0$, which allows achieving better performance/robustness indices, as in [21]. For a given maximum of the sensitivity function, $M_{\mathrm{s}}=\max \left|1 /\left(1+G_{c}(\mathrm{i} \omega) \mathrm{G}_{v x}(\mathrm{i} \omega)\right)\right|$, a time constant $\lambda$ is determined by solving two nonlinear algebraic equations (16) and (17)

$$
\begin{gathered}
\left|1 /\left(1+G_{c}(\mathrm{i} \omega) G_{v x}(\mathrm{i} \omega)\right)\right|^{2}-1 / M_{\mathrm{s}}^{2}=0 \\
\partial\left(\left|1+G_{c}(\mathrm{i} \omega) G_{v x}(\mathrm{i} \omega)\right|^{2}\right) / \partial \omega=0
\end{gathered}
$$

Further analysis enables us to represent $G_{\mathrm{c}}(s)$ as a PID/PI controller for VMC. A control system with a PID controller is realized by the control signal $v_{c}(t)$ defined by

$$
v_{c}(t)=k v_{f}(t)+k_{\mathrm{i}} \int\left(v_{r e f}(t)-v_{f}(t)\right) d t-k_{\mathrm{d}} \frac{d v_{f}(t)}{d t}
$$

where parameters $k, k_{\mathrm{i}}, k_{\mathrm{d}}$ are a proportional, integral, derivative gain, respectively, and $v_{f}(t)$ is a filtered sensed output signal $v_{o}(t)$, generated by $V_{f}(s)=V_{o}(s) /\left(T_{\mathrm{f}} S+1\right)$, and $T_{\mathrm{f}}$ is a time constant of filtration [22]. In a similar manner, a PI controller is obtained for CMC technique, with a control law obtained by substituting $k_{\mathrm{d}}=0$ into (18).

\section{SimULATION ANALYSIS AND PERFORMANCE EVALUATION}

The performances of VMC, PCMC and DCMC in the same operating conditions are analyzed and compared with simulations for the noninverting buck-boost converter operating in the CCM of inductor current which satisfies condition $L \geq L_{\min }=(1-D)^{2} R T_{s} / 2$.

TABLE 1: PARAMETERS OF THE NONINVERTING BUCK-BOOST CONVERTER

\begin{tabular}{l|c|c}
\hline \multicolumn{1}{c|}{ Parameter } & Symbol & Value \\
\hline Input voltage & $V_{\mathrm{g}}$ & $12 \mathrm{~V}$ \\
\hline Capacitor & $C$ & $400 \mu \mathrm{F}$ \\
\hline Inductance & $L$ & $100 \mu \mathrm{H}$ \\
\hline Load & $R$ & $5 \Omega$ \\
\hline Switching frequency & $f_{s}$ & $50 \mathrm{kHz}$ \\
\hline Output voltage & $V_{0}$ & $8 \mathrm{~V} / 18 \mathrm{~V}$ \\
\hline
\end{tabular}

According to Table 1 and relations (5)-(7) and (10)-(12), corresponding transfer functions are obtained for values of the output voltage: $V_{0}=8 \mathrm{~V}$. On the basis of that, the parameters of compensator $G_{c}(s)$ are determined and simulation analysis is done.

The transfer functions of obtained compensators are $G_{\mathrm{cPID}}^{\mathrm{VMC}}=\left(k+\frac{k_{i}}{s}+k_{d} s\right) /\left(T_{i} s+1\right), \quad$ for $\mathrm{VMC}$, where $k=0.019999, \quad k_{i}=8.8659, \quad k_{d}=0.00000145$, $T_{f}=k_{d} / N, \quad N \in(10,50) \quad$ is selected so that performance/robustness indices are not deteriorated, and 
$G_{\mathrm{cPI}}^{\mathrm{CMC}}=k \frac{T_{i} s+1}{T_{i} s}, \quad$ for $\mathrm{CMC}, \quad$ where $k=0.41638$,

$T_{i}=0.001425$.

In order to verify the effectiveness of the presented design procedure of feedback compensator, as well as rejection of disturbances of presented control methods, large step changes are introduced within simulation. The efficiency is not significantly affected by control algorithms, so the efficiency was not discussed and the objective of this paper was focused to show how considered control methods affect the performance of the closed loop system.

\section{A. Step change of input voltage}

Results of the output voltage control in a nominal regime, and for step changes of input voltage with considered methods are presented in Figs. 4 and 5. As it can be seen from Fig. 4, PCMC and DCMC methods are better than $\mathrm{VMC}$ regarding the rise time. It should be noticed that the obtained value of parameter $\lambda$ directly affects response speed for all considered methods.

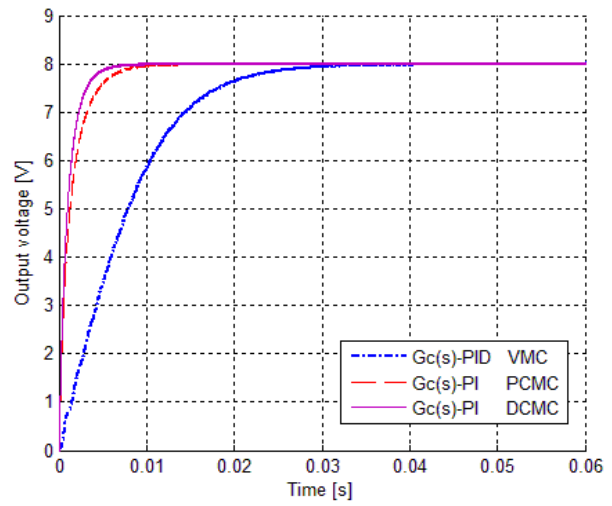

Fig. 4. Control of the output voltage to a value $V_{o}=8 \mathrm{~V}, V_{g}=8 \mathrm{~V}, D<0.5$.

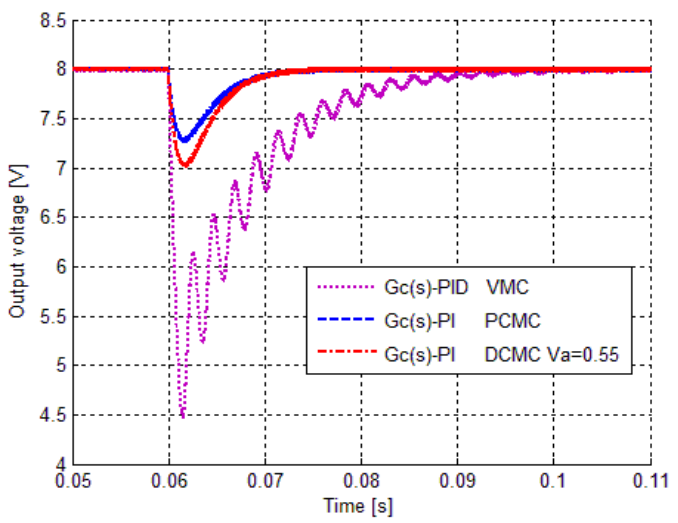

Fig. 5. Output voltage for a step change in input voltage $50 \%$ of nominal value from $12 \mathrm{~V}$ to $3 \mathrm{~V}$ at the time $0.06 \mathrm{~s}$.

Fig. 5 presents a comparison of responses to disturbance given in the form of a step change in input voltage. Obtained results show that PCMC and DCMC are superior to VMC since these methods lead to significantly better disturbance rejection. Besides, regarding that $G_{\mathrm{vd}}(s)$ is the second order linear non-minimum phase system, the presented compensation design technique leads to an oscillatory response to line disturbance for VMC.

In a similar manner, Fig. 6 presents how a compensator with PCMC suppresses a step change in input voltage, and with DCMC for different values of band voltage $V_{a}$.

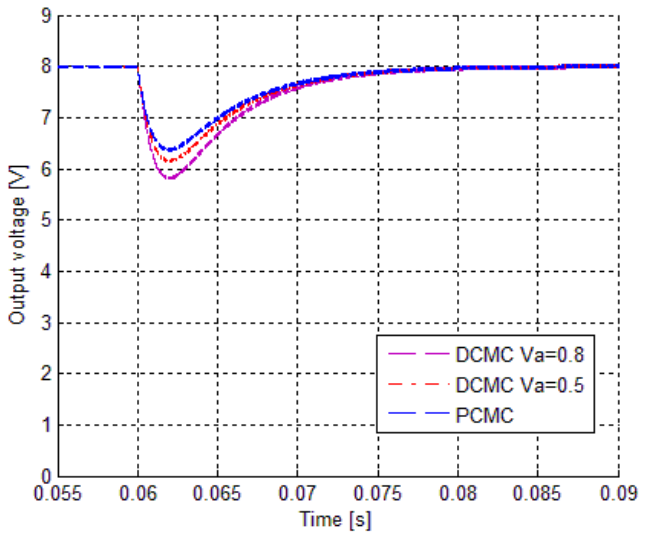

Fig. 6. Comparison of DCMC and PCMC methods for a step change introduced in input voltage from $12 \mathrm{~V}$ to $3 \mathrm{~V}$ at the time $0.06 \mathrm{~s}$.

Let us consider the case when input voltage contains periodic variations at the second harmonic of the system frequency $(100 \mathrm{~Hz})$. This often happens with off-line power supplies where variations are produced by a rectifier circuit [7]. Results for discussed control techniques are presented in Table 2, where $A_{g}$ is the magnitude of variations in $v_{g}(t)$, and $A_{o}$ is the magnitude of variations in $v_{o}(t)$.

\begin{tabular}{|c|c|c|c|c|}
\hline$A_{g}$ & $V_{o}[\mathrm{~V}]$ & $\begin{array}{c}A o / A g \\
(\mathrm{VMC})\end{array}$ & $\begin{array}{c}A_{o} / A_{g} \\
(\mathrm{PCMC})\end{array}$ & $\begin{array}{c}A_{o} / A_{g} \\
(\mathrm{DCMC})\end{array}$ \\
\hline \multirow[t]{2}{*}{$5 \% V_{\mathrm{g}}$} & 8 & 0.272 & 0.058 & 0.050 \\
\hline & 18 & 0.687 & 0.068 & 0.082 \\
\hline \multirow[t]{2}{*}{$10 \% V_{\mathrm{g}}$} & 8 & 0.261 & 0.044 & 0.038 \\
\hline & 18 & 0.640 & 0.191 & 0.207 \\
\hline \multirow[t]{2}{*}{$15 \% V_{\mathrm{g}}$} & 8 & 0.258 & 0.040 & 0.035 \\
\hline & 18 & 0.623 & 0.179 & 0.197 \\
\hline
\end{tabular}

From Table 2 we can draw a conclusion that output voltage ripple is significantly smaller with $\mathrm{CMC}$ than with VMC. Table 2 also shows that, if a duty factor $D<0.5$, DCMC gives smaller magnitude variations in $v_{o}(t)$ than PCMC, while for $\mathrm{D}>0.5$ PCMC is better according to this criterion.

\section{B. Step change of load resistance}

In order to show how a change in load current affects output voltage, a step response in the load resistance is introduced within simulation. Figs. 5 and 6 show that both CMC techniques improve dynamic performance and reject better line disturbances than VMC. Fig. 6 shows a comparison of PCMC and DCMC for several values of $V_{a}$, which leads to a conclusion that responses with DCMC, for boundary values of $V_{a}$ approach to the response of the system with PCMC. 


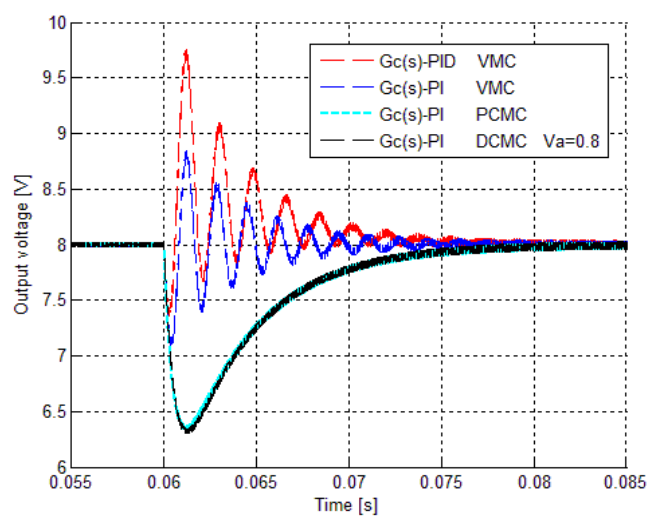

Fig. 7. Output voltage for a step change in the load resistance from $\mathrm{R}$ to $\mathrm{R} / 2$ at the time $0.06 \mathrm{~s}$.

From Figs. 4-6 it can be concluded that both CMC techniques improve dynamic performance and reject better line disturbances than VMC. It should be emphasized that design of compensator is easier for both CMC techniques in which compensator transfer functions are identical. Fig. 7 demonstrates that rejection of disturbance in load current is not adequate with VMC applying a PI/PID compensator, and that PCMC and DCMC show equal and better responses than $\mathrm{VMC}$ regarding disturbance rejection in load resistance.

\section{CONCLUSION}

Performance of the closed-loop system with VMC and two current control methods (PCMC and DCMC) and feedback compensator is examined. Simulation results prove that the system with CMC can perform better than VMC under system uncertainties and disturbances. In addition to improving the performance, CMC also simplifies the structure and design of the voltage feedback compensation which are some reasons of modifying and advancing existing control techniques.

\section{ACKNOWLEDGMENT}

I would like to express my gratitude to professors Milomir Šoja and senior assistant Srđan Lale for assistance during preparation of this work.

\section{REFERENCES}

[1] B. Sahu, G. A. Rincon-Mora, "A low voltage, dynamic, noninverting, synchronous buck-boost converter for portable applications", IEEE Trans. on Power Electronics, Vol.19, No. 2, pp. 443-452, March 2004

[2] C. Restrepo, J. Calvente, A. Cid-Pastor, A. E. Aroudi, R. Giral, "A Noninverting Buck-Boost DC-DC Switching Converter With High Efficiency and Wide Bandwidth", IEEE Trans. on Power Electron., vol. 26, No. 9, pp. 2490-2503, Sept. 2011.

[3] W. Chia-Ling, C. Chin-Hong, W. Kuo-Chun; K. I-Ting, "Design of an Average-Current-Mode Noninverting Buck-Boost DC-DC Converter With Reduced Switching and Conduction Losses" IEEE Trans. on Pow. Electronics, vol. 27, No. 12, pp. 4934-4943, Dec. 2012.
[4] Kim, Jong-Seok, Lee, Jae-Yoon, Choi, Byong-Deok, "Highefficiency peak-current-control non-inverting buck-boost converter using mode selection for single Ni-MH cell battery operation", Nordic Circuits and Systems Conf. (NORCAS): NORCHIP \& Inter.Symp. on System-on-Chip (SoC), pp.1-4, 26-28 Oct. 2015.

[5] G.K. Andersen, F. Blaabjerg, "Current programmed control of a single-phase two-switch buck-boost power factor correction circuit", IEEE Trans. on Ind. El., Vol. 53, pp. 263-271, Feb. 2006.

[6] J. Chen, D. Maksimovic and R. W. Erickson, "Analysis and design of a low-stress buck-boost converter in universal-input PFC applications," in IEEE Transactions on Power Electronics, vol. 21, no. 2, pp. 320-329, March 2006.

[7] R. Lin and R. Wang, "Non-inverting buck-boost power-factorcorrection converter with wide input-voltage-range applications," in Proc. 36th Annu. Conf. IEEE Ind. Electron. Soc., Nov. 2010, pp. 599-604.

[8] E. Schaltz, P. O. Rasmussen, A. Khaligh, "Non-inverting buck-boost converter for fuel cell applications", In Proc. 34th Annual Conference of IEEE Industrial Electronics, pp. 855-860, 2008.

[9] H.-K. Liao, T.-J. Liang, L. S. Yang, J.-F.,Chen, "Non-inverting buckboost converter with interleaved technique for fuel-cell system", IET Power Electronics, Vol. 5, pp. 1379-1388, 2012.

[10] Y. J. Lee and A. Emadi, "Integrated Bi-Directional AC/DC and DC/DC Converter for Plug-in Hybrid Electric Vehicle Conversion," IEEE Vehicle Power and Propulsion Conference, Arlington, TX, pp. 215-222, 2007.

[11] D. C. Erb, O. C. Onar and A. Khaligh, "An integrated bi-directional power electronic converter with multi-level AC-DC/DC-AC converter and non-inverted buck-boost converter for PHEVs with minimal grid level disruptions," IEEE Vehicle Power and Propulsion Conference, pp. 1-6., Lille, 2010.

[12] J.-K.Shiau, C.-J. Cheng, C.-E. Tseng, "Stability analysis of a noninverting synchronous buck-boost power converter for a solar power management system", IEEE International Conference on Sustainable Energy Technologies (ICSET) - Singapore, pp. 263-268, 24-27 Nov. 2008.

[13] R. R. de Carvalho Vaz, S. P. Pimentel and S. Araújo, "Analysis and control of a non-inverter Buck-Boost power DC-DC converter by state-space modeling and applied to PV systems under MPPT operation," Innovative Smart Grid Technologies Latin America (ISGT LATAM), 2015 IEEE PES, Montevideo, pp. 338-343, 2015.

[14] B. Johansson, "Improved Models for DC-DC Converters", Linc. Thesis, Lund University, Lund, 2003.

[15] Byungcho Choi, "Pulsewidth Modulated Dc-to-Dc Power Conversion", John Wiley \& Sons, Inc. Hoboken, New Jersey, pp. 245-639, 2013.

[16] Marian K. Kazimierczuk, "Pulse-width Modulated DC-DC Power Converters", J. Wiley and Sons, Ltd, 2008.

[17] A. V. Anunciada, M. M. Silva, "A New Current Mode Control Process and Applications", IEEE Trans. on Power Electronics, Vol. 6, No. 4, pp. 601-610, Oct. 1991.

[18] Srđan Lale, Milomir Šoja, Slobodan Lubura, Milan Radmanović, "Modeling and Analysis of New Adaptive Dual Current Mode Control", INDEL, Banja Luka, November 06-08, 2014.

[19] R. W. Erickson, D. Maksimović, "Fundamentals of Power Electronics", 2nd ed. Boston, Kluwer Ac. Publishers, pp 331-487., 2001.

[20] T. B. Šekara, M. B. Trifunović, V. Govedarica, "Frequency Domain Design of a Complex Controller under Constraints on Robustness and Sensitivity to Measurement Noise“, ELECTRONICS, vol. 15, pp. 40-44, 2011.

[21] K. J. "Advanced PID control, ISA-The instrumentation", Systems and Automation Society, 2006.

[22] Miroslav R. Mataušek, Tomislav B. Šekara, "PID controller frequency-domain tuning for stable, integrating and unstable processes, including dead-time“, Journal of Process Control, Vol. 21, Issue 1, pp. 17-27, January 2011.

[23] M. Bošković, "Voltage, peak current and dual current mode control methods of noninverting buck-boost converter," Telecommunications Forum Telfor (TELFOR), 2015 23rd, Belgrade, 2015, pp. 1024-1027. 